\title{
Trabalhadoras da saúde face à pandemia: por uma análise sociológica do trabalho de cuidado
}

\author{
Female healthcare workers and the Covid-19 pandemic in Brazil: \\ a sociological analysis of healthcare work
}

Silvana Maria Bitencourt (https://orcid.org/0000-0002-3183-373X) ${ }^{1}$

Cristiane Batista Andrade (https://orcid.org/0000-0003-1441-9171) ${ }^{2}$

${ }^{1}$ Instituto de Ciências Humanas e Sociais, Universidade Federal de Mato Grosso. Av. Fernando Corrêa da Costa 2367, Boa Esperança. 78060 900 Cuiabá MT Brasil. silvanasocipufmt@ gmail.com

${ }^{2}$ Departamento de Estudos sobre Violência e Saúde Jorge Careli, Escola Nacional de Saúde Pública Sérgio Arouca, Fundação Oswaldo Cruz. Rio de Janeiro RJ Brasil.

\begin{abstract}
The article aims to discuss the care provided by female healthcare workers in Brazil during the Covid-19 pandemic, based on a sociological analysis by authors who discuss such care as devalued and poorly paid work performed to a large extent by low-income women. The work involves social constructions of emotions and has used the body as a work instrument in care for others. In addition, the increasingly precarious nature of health work in Brazilian society, aggravated in recent decades, with an increase in temporary contracts, loss of labor rights, overload of tasks, and adverse work conditions, among others, adds to the increase in medical and hospital care in the Covid-19 pandemic. In this context, female healthcare workers experience lack of personal protective equipment, fear of coronavirus infection, concerns with their children and other family members, and illness and death of coworkers and themselves. The article highlights the need for government attention and management of healthcare work and professional societies, analyzing the work conditions female healthcare workers are experiencing in confronting the pandemic.
\end{abstract}

Key words Work conditions, Pandemic, Women workers, Gender analysis in health
Resumo Este texto tem como finalidade discutir o cuidado de trabalhadoras da área da saúde em face da Covid-19, sob a análise sociológica de autoras que o vêm discutindo enquanto um trabalho que é desempenhado, na sua maioria, pelas mulheres das classes populares, é desvalorizado e sofre baixa remuneração. É uma atividade que envolve as construções sociais das emoções e tem utilizado o corpo como um instrumento de trabalho no cuidado com o outro. Além disso, a precarização do trabalho em saúde na sociedade brasileira acirrada nas últimas décadas, como o aumento de contratos temporários, perdas de direitos trabalhistas, a sobrecarga das atividades, condições de trabalho precárias, dentre outros, soma-se com o aumento dos atendimentos médico-hospitalares diante da pandemia da Covid-19. Neste contexto, as trabalhadoras em saúde vivenciam as ausências de equipamentos de proteção individual, medo de contaminação pelo vírus, preocupações com filhos e familiares, vivências diante da morte $e$ do adoecimento de si e de colegas de profissão. Este texto aponta para a necessidade de atenção governamental, bem como para a gestão do trabalho em saúde e dos órgãos de classe profissional, analisando as condições de trabalho que as trabalhadoras em saúde estão vivendo no enfrentamento da pandemia.

Palavras-chave Condições de trabalho, Pandemia, Mulheres trabalhadoras, Análise de gênero na saúde 


\section{Introdução}

A ideia inicial deste artigo partiu das experiências das autoras sobre o trabalho de cuidado na contemporaneidade e as relações de gênero, entendendo-o como complexo e permeado pelas relações de poder entre quem é cuidado e aquele/a que realiza esse tipo de atividade. As mudanças no mundo do trabalho, tais como a precarização das relações laborais e as suas condições, serão discutidas ao longo do texto, estas que afetam tanto os homens, quanto as mulheres. No entanto, priorizaremos como foco de análise o trabalho das mulheres, estas que estão na linha de frente na pandemia da Covid-19 e precisam conciliar a função na área da saúde e as demandas familiares, considerando que ainda são vistas como as responsáveis pelo cuidado da família.

Utilizaremos, portanto, a denominação "trabalhadoras em saúde", entendendo-as como as que realizam a atividade de cuidado em saúde, ou seja, médicas, enfermeiras, técnicas de enfermagem, entre outras dessa área, sob a perspectiva da sociologia do trabalho e dos estudos de gênero.

Partindo dessa perspectiva, o texto analisa o trabalho de cuidado assalariado realizado pelas trabalhadoras na área de saúde, que estão na linha de frente, exercendo o cuidado em face da pandemia da Covid-19. Toma como foco a realidade brasileira e considera o contexto social, que confere ao país uma quantidade expressiva de desempregados/as, trabalhadores/as informais, pessoas que vivem aglomeradas em comunidades (favelas), assim como vivenciam um contexto de políticas de cuidado e de saúde insuficientes para $\mathrm{o}$ atendimento à população $\mathrm{o}^{1,2}$.

A afirmativa sobre o desemprego na sociedade brasileira é evidenciada pelos dados do Instituto Brasileiro de Geografia e Estatística (IBGE), pois mostram que, no primeiro trimestre de 2020, havia 12,9 milhões de pessoas desempregadas no Brasil $^{3}$. Se considerarmos as que deixaram de procurar uma atividade formal, ou seja, estão em empregos informais, esse número é mais significativo.

É preciso que se enfatize que a sociedade brasileira tem sofrido os impactos das reformas neoliberais no mercado de trabalho, como a precarização, o aumento do desemprego, a expansão do setor de prestação de serviços e dos processos de terceirização. E, nesse cenário, têm-se acirrado as perdas de direitos sociais e trabalhistas, sobretudo após a Reforma Trabalhista de 2017 (Lei $13.467 / 2017)^{4}$. A sociedade capitalista, a partir de sua constituição neoliberal, produz a precariedade e precarização do trabalho, entendidos como "a desregulamentação do emprego, a intensificação e a deterioração das condições do trabalho, a extensão da jornada, a redução dos salários, a crescente desproteção social, a difusão do sofrimento físico e/ou mental relacionados ao trabalho e o desemprego estrutural"s(p.5), a área de saúde não está fora dessas influências e dos novos modos de gestão, inclusive na área pública.

A precarização do trabalho que envolve a perda de direitos trabalhistas, com o acelerado processo de terceirização e, no caso específico das trabalhadoras em saúde, os baixos salários, leva-as a procurar e a permanecer em mais de um emprego, com vistas à subsistência. Essa afirmativa é corroborada por autores ${ }^{6}$ que consideram que, na área da saúde, a exemplo da enfermagem, sobretudo "os auxiliares e técnicos, vivem em condições cada vez mais precárias, com multiempregos e insegurança no ambiente profissional, o que os impede de exercer com dignidade suas atividades laborais"'(p.101).

De acordo com a legislação do SUS (Sistema Único de Saúde), no qual a saúde é tratada como direito constitucional aos habitantes do território brasileiro, independente da nacionalidade do/a usuário/a, cabe ao Estado a iniciativa de ações que promovam prevenção, promoção, assistência, recuperação e reabilitação da saúde das pessoas, entendendo-a como um "direito fundamental do ser humano"7. A partir desse contexto pandêmico, a garantia à saúde deve ser priorizada como política pública.

Embora a legislação brasileira garanta o direito à saúde ${ }^{6}$, nos últimos anos, o investimento nas áreas de saúde e educação sofre com os impactos da Emenda Constitucional no 95, que prevê o congelamento dos gastos do SUS e, portanto, configura um retrocesso na garantia dos direitos. Segundo os dados do Conselho Nacional de Saúde (CNS), a proposta de congelamento de gastos, nos vinte anos, implica na possível retirada de até 434 bilhões de reais somente do SUS. Tal política afeta diretamente a manutenção dos serviços da Estratégia da Saúde da Família (ESF), dos serviços de urgência e emergência, dos cuidados à Aids, câncer etc ${ }^{8}$. De acordo com essa reflexão, percebemos que a garantia de direito à saúde pública fica fragilizada com a redução expressiva dos investimentos nos serviços de saúde. Consequentemente, a população brasileira é impactada, assim como as condiçôes de trabalho dessas profissionais, com o menor investimento advindo de tal reforma fiscal.

É considerável pontuar que, desde o início da Pandemia, em fevereiro de 2020, as medidas protetivas, pautadas especialmente no isolamento 
social, não foram apoiadas totalmente pelo governo brasileiro, que adotou um discurso negacionista sobre a gravidade da doença, que já havia levado a óbito e infectado muitas pessoas fora do Brasil. Segundo seu discurso, o isolamento social seria uma medida muito prejudicial para a economia, pois ela não poderia parar. O grupo com maior risco de contágio, como as pessoas em asilamento ou privadas de liberdade, dependentes de sistema público, moradores das periferias brasileiras, soma-se às trabalhadoras que estão em contato direto com as mais vulneráveis ao coronavírus, inclusive as profissionais de saúde. Logo, necessita-se de um sistema de saúde com condições de atender de forma eficiente e digna, sobretudo dada à gravidade da Covid- $19^{10}$.

Por conseguinte, salientamos que, se há uma demanda mais crescente para os atendimentos em saúde para a prevenção e a assistência na pandemia, é evidente que o trabalho de profissionais de saúde às pessoas com Covid-19 tende, consequentemente, a aumentar. Por essa razão, as mídias jornalísticas brasileiras (G1 e Uol), nos meses de abril e maio de 2020, noticiaram as condições precárias no setor, como a ausência de Equipamentos de Proteção Individual (EPI) ou, quando da disponibilidade, o uso excessivo de um mesmo equipamento, tendo em vista a sua economia, além da sobrecarga com o aumento das demandas por atendimentos em saúde.

Partindo dessa perspectiva, o cenário possibilita refletir quão necessário é o trabalho de cuidado, seja nos espaços hospitalares e clínicos, seja no âmbito familiar. A percepção social de que o cuidado é central para a vida humana coloca em evidência o cuidado enquanto trabalho, em especial, aquele realizado na área de saúde pelas múltiplas formações profissionais (enfermagem, medicina, terapia ocupacional, psicologia, nutrição, fisioterapia, fonoaudiologia, dentre outros). Por meio dele, é evidenciado também que são as mulheres que têm realizado essa atividade, a qual tem como centralidade o desprendimento de atenções com o/a outro/a e os atendimentos das suas necessidades físicas, biológicas e emocionais ${ }^{11-13}$.

O trabalho de cuidado, portanto, não está deslocado do modo de produção capitalista, que, no seu desenvolvimento, explora as mulheres, que foi fundamental e necessário para a ascensão capitalista advinda do trabalho gratuito na esfera da reprodução ${ }^{14}$.

Tomando as mulheres trabalhadoras da saúde como foco do presente artigo, podemos verificar que são a maioria na área da saúde, sobretudo na enfermagem, pois, em recente pesquisa nacional sobre essa categoria, constatou-se que $85,1 \%$ são mulheres ${ }^{15}$. Além disso, são elas ainda que, ao deixarem seus postos, voltam para casa e, portanto, para o cuidado que não se esgota na esfera profissional, cabendo-lhes a conciliação entre vida familiar e produtiva ${ }^{16}$.

Tendo tal abordagem, este texto tem duas finalidades, que são: a) discutir as contribuições dos estudos das relações de gênero para analisar o trabalho de cuidado realizado pelas mulheres, especialmente em saúde, na sua dupla face: a esfera produtiva e a reprodutiva, enfatizando as especificidades do cuidado enquanto trabalho; b) analisar condições de trabalho, adoecimento e morte de trabalhadores/as da saúde em face da Covid-19 no Brasil. Para isso, trazemos o conceito da divisão sexual laboral e do trabalho de care, problematizando as desigualdades entre homens e mulheres e as condições nas quais estão expostas as mulheres na saúde. Posteriormente, discutimos o cuidado em saúde e a realidade vivida pelas trabalhadoras em saúde na pandemia da Covid-19.

\section{A divisão sexual do trabalho e o cuidado em saúde}

Partimos da concepção de que o trabalho é central na vida em sociedade, pois envolve as relações sociais e de poder, logo de dominação. Logo o conceito de divisão sexual do trabalho é igualmente central para compreender as desigualdades de gênero e os modos com que as mulheres têm se inserido no mercado, sendo essa concepção um ponto-chave ${ }^{16}$, a partir do entendimento de ser homem e mulher como construção social e histórica, para além da fundamentação biológica ${ }^{17}$, consequentemente, as relações sociais de sexo, que têm como base o trabalho ${ }^{16}$.

Assim, a divisão sexual do trabalho, como uma concepção analítica, permite elucidar, por um lado, que os homens estão na esfera produtiva, na qual, grosso modo, realizam atividades remuneradas. Por outro, são as mulheres que realizam o trabalho reprodutivo, que nem sempre é remunerado, logo é uma atividade gratuita. É também por meio dessa divisão que evidenciamos que os homens recebem maiores salários e, geralmente, estão em postos de maior valorização social e de decisões ${ }^{16}$.

A divisão sexual do trabalho foi essencial para o desenvolvimento do capitalismo nas sociedades modernas, que explorou as mulheres por meio de um discurso que naturalizou a função reprodutiva a partir do distintivo daquele feito "por amor", 
qual seja, quase uma essência da própria ideia de feminilidade "saber e estar disponível" para cuidar do outro ${ }^{14}$.

Interessa-nos salientar que, tal como reafirma Hirata $^{18}$, sob a perspectiva da divisão sexual do trabalho, a atividade doméstica, das quais participam as mulheres de maneira emblemática e real, é um trabalho e, portanto, deve ser considerada nas análises sobre gênero e suas confluências no mercado.

Conforme Hirata e Kergoat $^{19}$, é relevante considerar a condição de bipolarização entre as mulheres para se analisar a situação delas no mercado, pois a compra da função doméstica nos últimos tempos tem sido fundamental para as das classes médias construírem suas carreiras, fato que complexifica as relações de gênero, portanto de poder entre as mulheres para participar do trabalho. Leva-se em consideração, ainda, que a maternidade tem ficado sob a responsabilidade das mulheres e não avaliada como uma questão social, que precisaria da efetiva ajuda do Estado, das políticas públicas e do exercício de uma paternidade consciente, que dividiria as tarefas domésticas, incluindo o cuidado dos filhos, com suas companheiras ${ }^{20}$.

A partir de tal abordagem, portanto, trazemos as contribuições das produções teóricas feministas e metodológicas dos estudos do care, sobretudo de autores como Helena Hirata ${ }^{12}$, Natacha Borgeaud-Garciandía ${ }^{13}$, Ângelo Soares ${ }^{21} \mathrm{e}$ Pascale Molinier ${ }^{22-24}$, pois consideram o cuidado como trabalho.

Ao aproximarmos desse campo teóri$\mathrm{co}^{12,13,21-24}$, é possível conhecer as condições de trabalho nas quais estão expostas as trabalhadoras da saúde, as suas inserções e permanências no mercado, os salários e as jornadas, as formas de conciliação entre esfera produtiva e reprodutiva (cuidado com filhos e familiares, atividades domésticas etc.). Somam-se a isso a perspectiva das construções subjetivas e os desafios postos a elas, sobretudo no que diz respeito ao cuidado em saúde realizado em tempos de pandemia, tais como o medo da morte e do adoecimento, o ter que lidar com a sobrecarga devido ao aumento do número de pessoas que necessitam de atendimento, o cansaço físico e mental, os sentimentos de compaixão e de responsabilidade.

O trabalho de cuidado é complexo, pois envolve as interações entre quem cuida e quem é cuidado, bem como engendra as relações sociais para atender as necessidades humanas com vistas ao bem-estar e conforto, solicitando de quem cuida a responsabilidade pela ação $0^{13,21-24}$.
É através dele que cuidadoras experimentam sentimentos próprios diante da morte e do adoecimento alheio, realizam procedimentos para antever as necessidades das pessoas, ou seja, elaboram estratégias para atender as demandas do cuidado. E, nesse sentido, "a solicitude e a responsabilidade sentidas, assim como os significados que têm, não são dadas e naturais"'13 (p.44).

Assim sendo, Borgeaud-Garciandía ${ }^{13}$ considera que são construídas na dinâmica e nas tensões das relações de trabalho do cuidado no âmbito público ou privado. Dessa maneira, é preciso lidar com a morte e com os dilemas morais para a tomada ou não de decisões. Mas, ao mesmo tempo, existe um convívio diante da intimidade entre quem recebe e quem a realiza, uma vez que o reconhecimento da vulnerabilidade do outro é necessário para a condução do atendimento das necessidades de quem é cuidado ${ }^{13}$.

Sendo o care requerido em todas as sociedades, por pessoas em situações de vulnerabilidade ou não, realizado por especialistas ou não, ele exprime a sua extensão subjetiva para além da venda da força de trabalho na sociedade capitalista. É a partir das considerações sobre as construções subjetivas e o cuidado, que Pascale Molinier ${ }^{24}$ considera as experiências de sofrimento, compaixão, processos criativos e de afetos nas interações, com vistas à preservação da vida de quem é cuidado.

A perspectiva das construções subjetivas no e pelo trabalho de cuidado traz avanços para analisar as suas facetas e complexidades, pois, de acordo com Molinier ${ }^{22-24}$, existe uma invisibilidade dos saberes e fazeres de cuidar. Uma das contribuições trazidas pela autora é sobre o saber-fazer discreto, em que as antecipações para proporcionar conforto e bem-estar estão sempre presentes nas ações da cuidadora (remunerada ou não), sem que as pessoas percebam um gesto, o zelo ou a prevenção de uma complicação, por exemplo; sem contar as preocupações com o conforto físico e emocional da pessoa cuidada. Além disso, existe um saber-fazer que é aprendido nas formações técnicas, mas também pelas adversidades do cotidiano de trabalho, tal qual o encontro de soluções diante de um problema ${ }^{24}$.

Salientamos que, além do cuidado com o corpo do outro, o trabalho em saúde, especialmente daqueles que estão em contato direto com as pessoas, é permeado pelo uso do corpo. O conceito de trabalho corporal, que ficou durante muito tempo sem ser central para a sociologia do trabalho, agora parece ser indispensável, sobretudo nos avanços sobre o trabalho com e pelo corpo, 
em que as experiências das relações sociais podem apreender como trabalhadoras lidam e articulam-se com seus corpos e com os dos outros ${ }^{25}$.

A dimensão corporal no cuidado é também trazida por Soares ${ }^{21}$, pois os movimentos de deslocar, virar, carregar ou mudar as pessoas em uma cama, por exemplo, são utilizados para proporcionar bem-estar e conforto. Dito isso, é relevante sinalizar que, em diversos estudos, os adoecimentos de profissionais de saúde, relativos ao uso do corpo, têm sido evidenciados, tais como as lesões musculoesqueléticas na coluna, ocasionadas pelo constante carregamento de peso e deslocamento de pessoas nos leitos hospitalares ${ }^{26}$.

Outro ponto de vista trazido pelos estudos do care é sobre as emoções, pois, para Soares ${ }^{21}$, o cuidado é um tipo de atividade, em que os aspectos emocionais e relacionais são construídos social e coletivamente na e pela profissão, em que os sentimentos de amor, compaixão, confiança e afetividade se fazem presentes. No entanto, sentimentos hostis, de tristeza e tantos outros negativos podem vir à tona no exercício profissional ${ }^{21}$.

$\mathrm{E}$, se refletirmos sobre o contexto da pandemia, as emoções das que realizam atividade da saúde devem ser consideradas sob a premência de um arcabouço teórico que as considere, tal como sinaliza Fortino et al. ${ }^{27}$. Para elas, o trabalho requer, o tempo inteiro, o gerenciamento das emoções diante das dificuldades, das situações de violência, das injustiças, fúria, dentre outras. Da mesma forma, os prazeres, os contentamentos e a conquista da confiança. Se, por um lado, as expressões das emoções são requeridas em determinados momentos, por outro, existe a dissimulação de sentimentos que possam comprometer o desenvolvimento da atividade ou pôr em risco o emprego, já que a gestão pode prescrever o que se deve ou não externar por parte das trabalhadoras $^{27}$

Assim, considerar o panorama das emoções no cuidado é crucial, sobretudo na pandemia, pois pesquisas chinesas já sinalizam que os problemas nos atendimentos, desde a exaustão física e emocional, passando pelas dificuldades nas tomadas de decisões sobre a saúde das pessoas cuidadas, até o medo de serem infectadas pelo coronavírus e da morte. Ademais, existe o contexto familiar, visto que muitas têm receio de infectar seus familiares (pais idosos e filhos) ${ }^{28}$.

Embora o presente artigo considere, sobretudo, o trabalho de cuidado naquele em que há remuneração para tal, é importante considerar que ele não abrange apenas a esfera produtiva, mas também a privada, em que muitas contratam cuidadoras domiciliares, aspecto discutido por Borgeaud-Garciandía ${ }^{13}$, como babás, cuidadoras de idosos, empregadas domésticas e faxineiras, e portanto, valem-se de um cuidado que nem sempre requer formação profissional para tal. Isto posto, é nesse cenário que as trabalhadoras de saúde tomam suas decisões para, nesse momento da pandemia, escolher com quem e como ficam os cuidados de seus filhos e familiares, uma vez que creches, pré-escolas e escolas estão fechadas para a contenção da propagação do coronavírus, o que pode gerar dificuldades para conciliar o trabalho produtivo e reprodutivo.

\section{Trabalhadoras em saúde: adoecimentos e morte na Covid-19}

São as trabalhadoras da saúde que, ao contrário de boa parte da população, que está em isolamento ou distanciamento social devido ao controle do coronavírus, estão à frente dos atendimentos que são de alto risco, pois o vírus tem intensa e extensa propagação mundial ${ }^{28}$.

Como discutido anteriormente, a precarização do trabalho, inclusive na área de saúde, associada com a intensificação das atividades pautada no produtivismo, podem contribuir para desencadear doenças de ordem física e/ou psíquica na saúde e, consequentemente, promover o uso de medicamentos psicofármacos para lidar com as "dores da profissão"29-31. Partindo dessa perspectiva, a exposição aos riscos laborais a que estão submetidos/as, como os acidentes de trabalho e o adoecimento de seus corpos, tende a fazer parte do cotidiano da grande maioria das mulheres que trabalha com a saúde ${ }^{32}$, com a finalidade de produção de vida.

Se associarmos esse cenário dos atendimentos com a pandemia da Covid-19, é evidente que o aumento do número de casos intensifique a jornada na saúde. Embora ainda sejam escassas as pesquisas sobre as influências da pandemia na saúde e nas condições de trabalho das profissionais de saúde brasileiras, é possível dizer do aumento das demandas pelos atendimentos em saúde.

Em recente pesquisa sobre a oferta de leitos no país e de equipamentos de ventilação assistida, foi verificada a importância de se conter a propagação da doença para não sobrecarregar o sistema de saúde, bem como aumentar o número de leitos hospitalares e a construção de hospitais de campanha para que a população seja assistida, sobretudo em locais sem sistema de saúde capaz de atender demandas graves ${ }^{33}$. 
Se visitarmos os sites dos conselhos de classe, como da enfermagem ou da medicina, as condições vividas pelas trabalhadoras da saúde estão ruins, de modo a verificar que o Brasil é o país que mais teve mortes de profissionais do setor em decorrência da Covid-19, segundo o COFEN e o Conselho Internacional de Enfermeiros (ICN). Até a data de 27 de outubro de 2020 , foram confirmadas 454 mortes de trabalhadoras/es da equipe de enfermagem (enfermeiros, técnicos e auxiliares) no cenário brasileiro e 41.926 casos reportados ${ }^{34}$.

Em recente pesquisa sobre as condições de trabalho no Brasil, foram encontradas cerca de 17 mil inconformidades nos atendimentos da Covid-19, relatadas por 1.563 (56\% de mulheres) participantes. Dentre os maiores agravos, têm-se a ausência de: a) EPI, citada por 38,2\% (máscaras, aventais, óculos protetores, luvas etc.); b) insumos, exames e medicamentos (kit de exames de Covid-19, medicamentos etc.), por 18,9\%; c) equipe de profissional de saúde (enfermagem, medicina, limpeza, alimentação e fisioterapia), por $13,7 \%$. Igualmente, a pesquisa mostra a falta de produtos hospitalares, como álcool (líquido e em gel), papel toalha, sabonetes, desinfetantes e leitos hospitalares, dentre outros ${ }^{35}$.

O Conselho Federal de Enfermagem (Cofen), em nota, aponta o medo de infecção sentido pela categoria, o receio de transmissão para seus familiares (filhos e pais adoecidos), o pouco cuidado de si em decorrência do tempo que resta e da intensificação das atividades, as vivências diante das mortes de colegas e de pacientes. Além disso, o evidente desgaste físico de se trabalhar por horas em pé, com pouco tempo de repouso ${ }^{36}$.

Certamente, essas condições permeiam ou, pelo menos, relacionam-se com o adoecimento dessas trabalhadoras em saúde. E, dessa maneira, as vivências diante do cuidado retratam as violências pelas quais vêm passando, entendendo-as como aquelas que envolvem: "[...] a negligência em relação às condições de trabalho; e a omissão de cuidados, socorro e solidariedade diante de algum infortúnio, caracterizados pela naturalização da morte e do adoecimento relacionados ao trabalho" ${ }^{\prime 37}$ (p.30).

Assim, chamamos à atenção para as relações de gênero e as desvantagens das mulheres no mercado. Estas têm sido objeto de estudos e, de acordo com a União Europeia, são elas que mais têm sido expostas às doenças profissionais, acidentes de trabalho, violências, como os assédios, os empregos precários e com baixos salários, bem como possuem jornadas mais extenuantes e des- valorização salarial quando comparadas com os homens. Sem dúvida, "a desigualdade de gênero influencia as condições de trabalho e a forma como os atores as racionalizam"38(p.15), o que reitera que as condições de trabalho de mulheres se relacionam com a segregação sexual (trabalho de homem e mulher) nas inserções no mercado ${ }^{38}$.

Considerando que ainda não temos um prognóstico para lidar com o coronavírus, mesmo que medidas protetivas sejam acatadas pela população e possam diminuir o risco, como a higienização das mãos com o uso de álcool em gel e lavagem com água e sabão, bem como a utilização de máscaras, o isolamento e distanciamento social, podemos verificar que inúmeras profissionais da saúde têm sido contaminadas e não sabem a forma como contraíram o vírus. Portanto, as emoções, como medo de morrer, preocupação em contaminar familiares e ansiedade por não saberem como será o dia de amanhã, tendem a intensificar a pressão emocional que vivenciam.

Os corpos das profissionais de saúde tornaram-se números, como um narrou ao ser entrevistado sobre seu trabalho, que sentia muita tristeza de ver as vidas que importavam sendo agora somadas em números de "lápides" devido à intensificação das mortes diárias: "Hoje nós somos números, agora os nossos números de matrículas estão sendo substituídos por número de lápides" (profissional de saúde) ${ }^{39}$.

Os sentimentos gerados na pandemia têm transformado a realidade social, assim como as subjetividades femininas, sendo que a incerteza produzida diante da Covid-19 já se apresentava, considerando as consequências do projeto da modernidade ${ }^{40}$ perante as limitações do conhecimento científico para responder como será o amanhã. Nos termos weberianos, esse conhecimento apresentava limitações por não responder às indagações relativas ao sentido da existência humana, ou seja, o que devemos fazer e como devemos viver ${ }^{41}$, diante da realidade social apresentada.

No contexto antropocêntrico, no qual a ciência moderna foi compreendida como uma conquista humana, que resolveria todos os dilemas enfrentados pela sociedade, os preceitos religiosos, assim como todos os outros tipos de conhecimentos, foram deixados em segundo pla$\mathrm{no}^{41}$, pois a ciência emerge como saber único e verdadeiro da modernidade. Assim, é afirmada a hegemonia do conhecimento ocidental, branco e masculino. Os conhecimentos produzidos e desenvolvidos pelas mulheres sobre o corpo feminino e o trabalho reprodutivo foram ignorados 
na história da ciência moderna, o que contribuiu para o desenvolvimento do capitalismo, ao explorar as mulheres, a partir do trabalho de reprodução social ${ }^{42}$.

A ciência, contudo, deve ser compreendida como um tipo de conhecimento que se firmou diante de um cenário favorável para se estabelecer, logo tem uma história compartilhada a partir de determinados paradigmas, que podem entrar em crise, dependendo do grau de aceitação que os membros da comunidade científica compreendem a partir do período histórico analisado ${ }^{43}$.

Crise foi dita no sentido de que a sociedade irá se transformar, pois todas as pessoas, independente de classe, raça, gênero ou nacionalidade, vivenciam mudanças expressivas nos seus modos de vida e na forma de lidar com a temporalidade de seus corpos e emoções, pois ainda não há uma previsão de como construirão as relações sociais no pós-pandemia e quais marcas gerarão na vida das pessoas, principalmente com as mortes decorridas da Covid-19.

Fala-se que a vida "nunca mais será como antes”, e esta ideia de não ter uma previsão de futuro pode deixar muitos/as com grandes problemas emocionais, considerando que estamos socialmente condicionados em pensar no amanhã. Assim, temos dificuldades de lidar com a experiência do agora, a fim de traduzi-la, logo muitos saberes nesta situação podem ser desperdiçados $^{44}$, se não estivermos atentos à nova realidade que se apresenta.

A pandemia do coronavírus assolou a ideia de que tínhamos um quadro de referências explicativas, portanto "racionais", para lidar com os problemas do amanhã; a ideia de crise se acentua nesse contexto, fragilizando todos os referenciais modernos que herdamos, moldados por uma racionalidade viciada, pautada na dicotomia de nós e os outros ${ }^{45}$, ou seja, as tragédias vivenciadas pelos outros não nos atingiriam.

Essa racionalidade do mundo capitalista ocidental se estabeleceu, extinguindo muitas populações humanas ${ }^{46}$, sendo que, na contemporaneidade do século XXI, o capitalismo tem se afirmado através do consumo imediato, o "desfrutá-lo”, permitindo que o indivíduo acione os mecanismos de suportabilidade e os dispositivos de regulação das sensações. Cria-se, assim, sua política de sensibilidade, ou seja, organiza seu cotidiano para não refletir sobre as desigualdades sociais geradas e sustentadas pelo capitalismo ${ }^{47}$.

Vale lembrar que o cuidado com os corpos depois da morte também é uma atividade das profissionais de saúde. Após o óbito por Co- vid-19, por vezes, os corpos são colocados em sacos plásticos, sem roupas, tendo seus caixões lacrados, sem a possibilidade de as famílias se despedirem de seus entes queridos, nem podendo escolher o traje para o ritual de despedida. E quem presencia o grande número de mortos nos hospitais, tanto de colegas como de pacientes, e encontram pessoas que buscam uma palavra de consolo porque perdeu ou está perdendo um ente querido, tem sido a profissional da saúde, a que precisa lidar com as suas emoções para "dar uma palavra de conforto" ao que não verá nunca mais o corpo de seu familiar. E, assim, podemos considerar a dimensão emocional ${ }^{21}$ que envolve o trabalho de cuidado, já discutida anteriormente.

Elias $^{48}$, ao analisar as emoções diante da morte e dos mortos, apresenta que o terror e o temor são despertados na consciência dos vivos, pois quem sofre é quem ainda permanece vivo, já que não se sabe sobre os sentimentos, em termos científicos, daqueles que se foram.

Em paralelo ao cenário de inúmeras mortes, é realizado o ritual de comemoração nos hospitais dos pacientes recuperados da Covid-19, com balões brancos e aplausos. O corpo, nesse contexto, é compreendido como uma "máquina" que conseguiu se recuperar, foi resistente, portanto, merecedor das comemorações, isso fica mais evidente quando se trata da recuperação de pessoas muito idosas. A representação positiva dos discursos do corpo resistente aparece como uma ideia de que teve melhor saúde para se recuperar da doença.

A ideia de finitude corporal, as perdas e as limitações que se expressam no corpo nos revelam que todas as crises humanas têm como foco o corpo e as emoções ${ }^{49}$. Contudo, as emoções sobre o trabalho de cuidado ${ }^{21}$ prestadas aos outros são evidenciadas nos sentimentos de alegria diante da recuperação de uma pessoa ou da tristeza quando o corpo cuidado não conseguiu resistir à doença da Covid-19.

Analisamos que a sessão de aplausos diários surge como uma forma de agradecimento coletivo ${ }^{49}$, afirmando a necessidade primordial de afirmação destas trabalhadoras. No entanto, a representação de um coletivo de heroínas na saúde pode contribuir não somente para uma valorização social delas, mas também para reforçar a pressão de serem corpos invencíveis para cuidar, portanto, dilui-se o ser individual, o corpo que tem uma vida além do trabalho.

Partindo dessa perspectiva, o contexto também se mostra favorável ao capital continuar explorando, de forma desumana, esses corpos. 
Agora o elogio pode ser um antídoto para silenciar vozes que querem trabalhar, mas precisam de condições adequadas para desenvolver suas atividades que foram vistas como necessárias, essenciais e valiosas no contexto desta pandemia. Considera-se que as heroínas se tornaram "simples enfermeiras" ${ }^{\prime 4}$, portanto pessoas que precisam também de cuidados, sobretudo na realidade brasileira, em que a precarização do trabalho está posta. Como analisamos anteriormente, o aumento dos atendimentos da Covid-19 e as precárias condições de trabalho permitem questionar o peso da representação de "heroínas" que essas mulheres estão recebendo nesta pandemia.

\section{Conclusões}

Diante do cenário de grande crise sanitária que vem enfrentando o Brasil, temos a percepção de que as mortes e os adoecimentos ocorridos em decorrência da Covid-19 apontam para a necessidade de um sistema de saúde público de qualidade, tal como o proposto pelo SUS, para $\mathrm{o}$ atendimento integral e universal da população de norte a sul do país para todas as classes sociais.

É também neste período que fica evidenciada a centralidade do trabalho de cuidado, como aquele que produz e mantém a vida social na esfera produtiva e reprodutiva, mas que, ao mesmo tempo, possui suas contradições, que vão desde a mercantilização (quem paga e quem oferece o serviço de cuidado, quem tem acesso ou não ao cuidado profissional, quem realiza a formação profissional e quem paga por ela), em um país desigual como o Brasil, até a concretude da atividade, que é feita, na maioria, pelas mulheres das classes populares.

E, assim, este artigo reflexivo aponta para a necessidade de atenção governamental a gestão do trabalho em saúde e dos órgãos de classe profissional, percebendo as más condições a que estão vivendo no enfrentamento da pandemia. Não é possível que essas condições possam ser escamoteadas diante de tanto adoecimento e mortes de profissionais deste setor.

Dessa maneira, a partir da perspectiva da análise sociológica do trabalho de cuidado, foi possível entender que muitas mulheres, enquanto trabalhadoras da área de saúde, estão vivenciando inúmeros desafios, inclusive os de adoecimentos e mortes de colegas de trabalho, além da precarização e diminuição dos investimentos na área de saúde pública, que já assolavam o setor antes até mesmo do contexto pandêmico.

Ademais, os medos e as emoções relativos a essas vivências precisam ser pensados de modo que, coletivamente, as ações para a saúde dessas profissionais sejam garantidas em um momento de negacionismo da ciência como o que vivemos e de intensificação das demandas de trabalho, seja em casa ou na área da saúde.

\section{Colaboradores}

SM Bitencourt e CB Andrade trabalharam igualmente na concepção, análise, redação, revisão crítica e na aprovação da versão a ser publicada. 


\section{Referências}

1. Veras R. Envelhecimento populacional contemporâneo: demandas, desafios e inovações. Rev Saúde Pública 2009; 43(3):548-554.

2. Camarano AA, organizador. Cuidados de longa duração para a população idosa: um novo risco social a ser assumido? Rio de Janeiro: IPEA; 2010.

3. Instituto Brasileiro de Geografia e Estatística (IBGE). Desemprego-IBGE [Internet]. 2020 [acessado 21 Maio 2020]. Disponível em: https://www.ibge.gov.br/explica/desemprego.php

4. Pochmann M. Tendências estruturais do mundo do trabalho no Brasil. Cien Saude Colet 2020; 25(1):8999.

5. Morosini MVGC. Precarização do trabalho: particularidades no setor saúde brasileiro. Trab Educ Saúde 2016; 14 (Supl. 1):5-7.

6. Machado MH, Koster I, Aguiar Filho W, Wermelinger MCMW, Freire NP, Pereira EJ. Mercado de trabalho e processos regulatórios - a Enfermagem no Brasil. Cien Saúde Colet 2020; 25(1):101-112.

7. Brasil. Lei 8.080, de 19 de setembro de 1990. Dispõe sobre as condições para a promoção, proteção e recuperação da saúde, a organização e o funcionamento dos serviços correspondentes e dá outras providências. Diário Oficial da União 1990; 20 set.

8. Santos R. A PEC 55 e as ofensivas nefastas à Constituição. 2016. Centro de Estudos Estratégicos da Fiocruz [Internet]. [acessado 22 Maio 2020]. Disponível em: http://www.cee.fiocruz.br/?q=node/493\&qt-conteudosrelacionados $=1$

9. TV Cidade Verde. Em pronunciamento Bolsonaro diz que coronavírus é gripezinha [Internet]. [acessado 22 Maio 2020]. Disponível em: https://www.youtube. com/watch?v=b7KAP31EqTU.

10. Campos GWS. O pesadelo macabro da Covid-19 no Brasil: entre negacionismos e desvarios. Trab Educ Saúde 2020; 13(3):1-5.

11. Kergoat D. O trabalho, um conceito central para os estudos do gênero? In: Maruani $\mathrm{M}$, organizadora. Trabalho, logo existo? Perspectivas feministas. Rio de Janeiro: FGV Editora; 2019. p. 287-294.

12. Hirata H. Subjetividade e sexualidade no trabalho de cuidado. Cad Pagu 2016; 46(1):151-163.

13. Borgeaud-Garciandía N. Cuidado y responsabilidad. Estud Av 2020; 34(98):41-56.

14. Federici S. O ponto zero da revolução. Trabalho doméstico, reprodução e luta feminista. São Paulo: Elefante; 2019.

15. Silva MCN, Machado MH. Sistema de Saúde e Trabalho: desafios para a Enfermagem no Brasil. Cien Saúde Colet 2020; 25(1):7-13.

16. Kergoat D. Divisão sexual do trabalho e relações sociais de sexo. In: Hirata H, Laborie F, Doaré HL, Senotier D, organizadoras. Dicionário crítico do feminismo. São Paulo: Ed. Unesp; 2009. p. 67-75.

17. Scott JW. Gênero: uma categoria útil de análise histórica. Edu Realidade 1995; 20(2):71-99.

18. Hirata HS. Nova divisão sexual do trabalho? Um olhar voltado para a empresa e a sociedade. São Paulo: Boitempo; 2002.
19. Hirata $\mathrm{H}$, Kergoat $\mathrm{D}$. Les paradigmes sociologiques à l'épreuve des catégories de sexe: quel renouvellement de l'épistémologie du travail? In: Durand JP, Linhart $\mathrm{D}$, organizadoras. Les ressorts de la mobilisation au travail. Toulouse: Octarès; 2005. p. 263-272.

20. Bitencourt SM. A maternidade para um cuidado de si: desafios para a construção da equidade de gênero. Estud Sociol 2019; 24(47):261-281.

21. Soares A. As emoções do care. In: Hirata HS, Guimarães NA, Fontes A, organizadoras. Cuidado e cuidadoras: as várias faces do trabalho do care. São Paulo: Atlas; 2012. p. 44-59.

22. Molinier P. Ética e trabalho do care. In: Hirata HS, Guimarães NA, Fontes A, organizadoras. Cuidado e cuidadoras: as várias faces do trabalho do care. São Paulo: Atlas; 2012. p. 29-43.

23. Molinier P, Laugier S, Paperman P. Qu'est-ce que le "care"? Souci des autres, sensibilité, responsabilité. $\mathrm{Pa}$ ris: Payot; 2009.

24. Molinier P. El cuidado puesto a prueba por el trabajo: vulnerabilidades cruzadas y saber-hacer discreto. In Borgeaud-Garciandía N, organizadora. El trabajo de cuidado. Buenos Aires: Fundación Medifé Edita; 2018. p. 187-209.

25. Wolkowitz C. The Social Relations of body Work Work Employment Soc 2002; 16(3):497-510.

26. Neves M, Serranheira F. A formação de profissionais de saúde para a prevenção de lesões musculoesqueléticas ligadas ao trabalho a nível da coluna lombar: uma revisão sistemática. Rev Port Saúde Pública 2014 32(1):89-105.

27. Fortino S, Jeantet A, Tcholakova A. Émotions au travail, travail des émotions. Présentation du Corpus. $L a$ nouvelle revue du travail 2015; 6:1-6.

28. The Lancet. Covid-19: protecting health-care workers. Lancet 2020; 395(10228):922.

29. Luz MT. Cultura Contemporânea e Medicinas Alternativas: novos paradigmas em saúde no fim do século XX. Physis 2005; 15(Supl.):145-176.

30. Felli VEA. Condições de trabalho de enfermagem e adoecimento: motivos para a redução da jornada de trabalho para 30 horas. Enferm Foco 2012; 3(4):178181.

31. Rosado IVM, Russo GHA, Maia EMA. Produzir saúde suscita adoecimento? As contradições do trabalho em hospitais públicos de urgência e emergência. Cien Saúde Colet 2015; 20(10):3021-3032.

32. Gondim AA, Pinheiro JAM, Mendes CF, Neves L. O impacto do processo de precarização laboral em serviços de saúde. Rev SBPH 2018; 21(1):56-73.

33. Noronha KVMS, Guedes GR, Turra CM, Andrade MV, Botega L, Nogueira D, Calazans JÁ, Carvalho L, Servo L, Ferreira MF. Pandemia por Covid-19 no Brasil: análise da demanda e da oferta de leitos hospitalares e equipamentos de ventilação assistida segundo diferentes cenários. Cad Saúde Pública 2020;36(6):1-17.

34. Conselho Federal de Enfermagem (Cofen). Observatório da Enfermagem. Profissionais infectados com Covid-19 informados pelos enfermeiros responsáveis Técnicos/coordenadores [Internet]. 2020 [acessado 2020 Jun 11]. Disponível em: http://observatoriodaenfermagem.cofen.gov.br/ 
35. Conselho Federal de Medicina (CFM). CFM divulga primeiro levantamento com denúncias de médicos da linha de frente contra a pandemia [Internet]. 2020 [acessado 2020 Maio 28]. Disponível em: http://portal.cfm. org.br/index.php?option $=$ com_content\&view $=$ article\&id=28695:2020-05-15-11-57-06\&catid=3

36. Conselho Federal de Enfermagem (Cofen). Enfermeira faz relato sobre mortes por coronavírus em UTI [Internet]. 2020 [acessado 2020 Maio 9]. Disponível em: http://www.cofen.gov.br/enfermeira-faz-relatosobre-mortes-por-coronavirus-em-uti_79629.html

37. Oliveira RP, Nunes MO. Violência relacionada ao trabalho: uma proposta conceitual. Saúde Soc 2008; 17(4):22-34

38. Monteiro R, Freitas V, Daniel F. Condições de trabalho num universo profissional feminizado. Rev Estud Fem 2018; 26(2):1-19.

39. G1. Falta de amparo [Internet]. 2020 [acessado 2020 Maio 1]. Disponível em: https://g1.globo.com/globonews/globonews-em-ponto/video/coronavirus-enfermeiros-do-rio-alegam-falta-de-amparo-e-equipamentos-em-utis-8503345.ghtml

40. Giddens A. As consequências da modernidade. São Paulo: Editora UNESP; 1991.

41. Weber M. A ciência como vocação. In: Weber M. Ensaios de sociologia. Rio de Janeiro: LTC; 1982. p. 154183.

42. Federici S. Mulheres e caça às bruxas. São Paulo: Boitempo; 2019.

43. Kuhn T. A estrutura das revoluções científicas. São Paulo: Perspectiva; 2009.

44. Santos BS. Para uma sociologia das ausências e uma sociologia das emergências. Rev Crítica Cien Soc 2002; 63:237-280.
45. Santos BS. Para um novo senso comum: a ciência, o direito e a política na transição paradigmática. São Paulo: Cortez; 2011.

46. Berman M. Introdução. In: Berman M. Tudo que é sólido se desmancha no ar: a aventura da modernidade. São Paulo: Cia das Letras; 1986. p. 15-35.

47. Scribano A. Disfrútalo! Una aproximación a la economía política de la moral desde el consumo. Buenos Aires: Elaleph.com; 2015.

48. Elias N. A solidão dos moribundos: seguido de "envelhecer ou morrer". Rio de Janeiro: Zahar; 2001.

49. Scribano A, De Sena A. The new heroes: applause and sensibilities in the era of the Covid-19. Culture Studi Soc 2020; 5(1):273-285.

Artigo apresentado em 16/06/2020

Aprovado em 26/11/2020

Versão final apresentada em 28/11/2020

Editores-chefes: Romeu Gomes, Antônio Augusto Moura da Silva 